\title{
El agente urbanizador en la ley 2/2012 y su necesario ajuste a las normas de la contratación del sector público
}

\author{
Alejandro Criado Sánchez \\ Doctor en Derecho \\ Abogado
}

\section{RESUMEN}

En este trabajo se abordan las cuestiones jurídicas más relevantes que plantea el agente urbanizador en la legislación urbanística de Andalucía tras la Ley 2/2012, de 30 de enero, de modificación de la Ley 7/2002, de 17 de diciembre, de Ordenación Urbanística de Andalucía. Además, junto al balance de la nueva regulación sobre el sistema de compensación, se analiza la relación del agente urbanizador en Andalucía con la legislación de contratos del sector público y se proponen algunas alternativas de lege ferenda para una mejora de la regulación vigente.

Palabras clave: "agente urbanizador", "legislacion de contratos del sector público", "Ley 2/2012"

\section{ABSTRACT}

This article study the most relevant legal issues raised by the developer in town planning law Andalusia after the Law 2/2012 of January 30, amending the Law 7/2002 of December 17, Urban Planning Andalusia. Furthermore, with the balance of the new regulations on the compensation sistem, analyzes the relationship of the "agente urbanizador" in Andalusia with the law of public sector contracts, and suggests some alternatives lege ferenda for better regulation in force.

Key words: "developer" "law of public sector contracts" "Law 2/2012" 


\section{CONSIDERACIONES GENERALES Y CONCLUSIONES PRE- VIAS}

La Ley de modificación de la LOUA tiene como objetivo la adaptación de esta norma a la Ley estatal del Suelo y, a la vez, la introducción de algunas reformas sustantivas, entre las que cabe destacar el objeto de este trabajo: el agente urbanizador.

Podemos afirmar que el balance de la norma es desigual: por una parte, el nuevo texto en ningún caso supone un cambio sustancial del régimen jurídico ni llega al nivel de profundidad y calidad de la regulación de Comunidades Autónomas como Extremadura, Castilla-La Mancha o Valencia. Por otra parte, supone un avance muy interesante en la buena dirección de la ejecución del planeamiento, haciendo atractiva la figura del agente urbanizador para los empresarios en Andalucía e incorporando algunas mejoras técnicas a la regulación existente, aún recelosa del agente urbanizador y protectora del derecho de los propietarios del suelo.

En relación con estos aspectos positivos, debemos asimismo destacar los siguientes contenidos: a) Se mejora la regulación actual del agente urbanizador y lo convierte en una alternativa viable para un empresario urbanizador; b) Se atiende una de las preocupaciones del legislador andaluz: la protección del propietario, 3) Se afronta la coordinación de esta normativa con la legislación de contratos del sector público, aunque con una solución técnica que sigue siendo mejorable ${ }^{1}$.

\section{EL CONCEPTO Y NATURALEZA JURÍDICA DE AGENTE URBANIZADOR}

El origen de la figura del agente urbanizador se encuentra en la Ley 6/1994, de 15 de noviembre, Reguladora de la Actividad Urbanística de la Comunidad Valenciana, de la mano de un grupo de expertos urbanistas entre los que cabe

\footnotetext{
${ }^{1}$ Sobre las líneas generales de mejora de esta regulación, véase: A. J. Criado Sanchez (2011): "El agente urbanizador en el anteproyecto de Ley de adaptación de la LOUA al TRLS 08", Revista de Urbanismo, julio, 2011, http://www.reurbanismo.com. En relación a las modificaciones del entonces anteproyecto de Ley de adaptación de la LOUA al TRLS, véase asimismo la entrevista a uno de los redactores de este texto legal, Gerardo Roger Fernández Fernández, cuyas respuestas versan sobre las cuestiones más novedosas sobre el agente urbanizador en España, Revista de Urbanismo, abril, 2011, (http://www.reurbanismo.com).
} 
destacar Javier García Bellido², Gerardo Roger Fernández ${ }^{3}$, Luciano Parejo Alfonso o Silvestre Martínez, que venian abogando desde hacía años por la concurrencia empresarial en la ejecución del planeamiento.

En líneas generales, el agente urbanizador pretendió desde sus inicios convertir la ejecución de planeamiento en una actividad esencialmente pública mediante su gestión indirecta, de forma similar a como se desarrolla en los países de nuestro entorno como Francia o Reino Unido.

El objetivo del agente urbanizador fue desde el principio intentar agilizar la ejecución del planeamiento de los sistemas tradicionales de ejecución, especialmente el más utilizado, el de compensación, y crear modelo alternativo de ejecución de planeamiento con las siguientes ventajas:

a) Un modelo más simple y rápido que el de compensación

b) Se profesionaliza la ejecución de planeamiento, que pasa de depender de los propietarios que no tienen por qué tener la capacidad profesional y económica necesaria, a sacarse a concurso público para su ejecución por empresas especializadas

c) Se liberaliza el mercado de suelo, al permitir crear una mayor oferta de suelo urbanizado y por tanto una disminución de su precio y el de la vivienda

\footnotetext{
${ }^{2}$ Ya apuntaba desde hacía años la necesidad de liberalización del mercado de suelo a través de la libre concurrencia empresarial para la realización de la obra urbanizadora, de la misma forma que el resto de obras públicas. García Bellido, J. y García de Diego; (1.993), «La liberalización efectiva del mercado del suelo. Escisión del derecho de propiedad inmobiliaria en una sociedad avanzada». Ciudad y Territorio, 95-96. Páginas 175 a 198. "Esperemos que ahora no pase como cuando Cerdá -viendo la imposibilidad ideológica y económica de aplicar tales medidas, ya que en España ni existían grandes empresas constructoras para afrontar ese reto ni se podía eludir la fuerte carga ideológica de la propiedad ruralproponía en 1.861 la reparcelación y pago de la urbanización entre los que se beneficiaran directamente de las mejoras urbanas; medidas hoy obvias y que tardarían casi un siglo en recogerse y aplicarse, hasta la LS 56, por la resistencia de los que, precisamente, se beneficiaban más sin ella. Ya llevamos un siglo y un tercio desde que propuso las formas de libre concurrencia empresarial, como en las obras públicas y el ferrocarril, aplicándolas analógicamente para la construcción de las ciudades."

${ }^{3}$ Escribió un importante número de artículos sobre la nueva figura tras su creación, entre otros (Fernández Fernández, G. R. (1993), «Necesidad y oportunidad de una visión alternativa al tratamiento legal del proceso urbanístico", Ciudad y Territorio, 95-96, P. 91), exponiendo lo siguiente: "El objeto prioritario de la nueva regulación sería la potestad de urbanizar. El principal sujeto protagonista de la acción urbanística no sería ya el "propietario", sino el urbanizador, y el final del proceso urbanístico no es la edificación sino que sería un continuo que abarca la urbanización, la edificación, la conservación, la rehabilitación, la sustitución y reurbanziación, y en el que la producción de las infraestructuras y servicios públicos de urbanización tendría un papel principal."
} 
Una buena definición del agente urbanizador la encontramos en el artículo 119.1 de la Ley 16/2005, de 30 de diciembre, Urbanística Valenciana:

El urbanizador es el agente público responsable del desarrollo y ejecución de las actuaciones urbanisticas señaladas en la presente ley, que comprenderán en todo caso la de redactar los documentos técnicos que se establezcan en las bases, proponer y gestionar el correspondiente proyecto de reparcelación y contratar al empresario constructor encargado de la ejecución del proyecto de urbanización, en los supuestos y conforme a las condiciones establecidas en esta ley. El urbanizador está obligado a financiar el coste de las inversiones, obras, instalaciones y compensaciones necesarias para la ejecución del programa, que deberá ser garantizado en forma y proporción suficientes, pudiendo repercutir dicho coste en la propiedad de los solares resultantes.

El agente urbanizador tiene dos características esenciales:

a) Es un agente público, lo que da a entender que es una persona privada o pública, es decir, un empresario o una administración. Además, tiene una responsabilidad pública como consecuencia de un concurso público y no por ser propietario, dado que no tiene por qué serlo.

b) Es el responsable de la ejecución de planeamiento, al igual que una junta de compensación. Para ello, elabora el planeamiento de desarrollo si es necesario, así como el proyecto de urbanización y reparcelación. También puede llevar a cabo las obras de urbanización o bien gestionar su contratación.

En relación a la naturaleza jurídica de la relación entre el agente urbanizador y la administración actuante es claramente de contrato administrativo, de ahí la necesidad de que su regulación urbanística se ajuste a lo establecido en la Ley de Contratos del Sector Público. Dado que la Ley de Contratos del Sector Público no regula el "contrato de gestión urbanizadora" o el "contrato de urbanización" ", y dado que el urbanismo es competencia autonómica, actualmente, el ajuste de la legislación urbanística reguladora del agente urbanizador a la Ley de Contratos del Sector Público debe venir de la mano de los contratos administrativos de naturaleza especial ${ }^{5}$. La relación jurídica entre agente urbanizador y administración debe por tanto considerarse un contrato admi-

\footnotetext{
${ }^{4}$ Ya se apuntó en CRIADO SÁNCHEZ (2007): «El agente urbanizador y la legislación de contratos de las Administraciones Públicas», Revista de Derecho Urbano y del Medio Ambiente, núm. 233.

${ }^{5}$ Así lo considera también GIMENO FELIU (Gimeno Feliu, J.M.;(2010), "Actividad urbanística y contratos públicos: la lógica publicidad concurrencia en las infraestructuras públicas"): "Y es que no cabe iden-
} 
nistrativo de naturaleza especial, que se regula en el artículo 19.1.b) de la LCSP, que los define de la siguiente forma:

Los contratos de objeto distinto a los anteriormente expresados, pero que tengan naturaleza administrativa especial por estar vinculados al giro o tráfico específico de la $\mathrm{Ad}$ ministración contratante o por satisfacer de forma directa o inmediata una finalidad pública de la específica competencia de aquélla, siempre que no tengan expresamente atribuido el carácter de contratos privados conforme al párrafo segundo del artículo 20.1, o por declararlo así una Ley.

En definitiva, dado que en la actualidad, urbanismo y contratación pública son materias distintas, atribuidas a Comunidades y al Estado, es por lo que la consideración de la relación jurídica entre agente urbanizador y la administración como contratos administrativos de naturaleza especial sea la mejor forma de encaje y coordinación entre legislación de contratos del sector público y legislación urbanística. Ello sin perjuicio de ser de aplicación al agente urbanizador los aspectos generales de la Ley de Contratos del sector público con carácter supletorio y, a nuestro entender, debería ser de aplicación directa al agente urbanizador los requisitos del contratista del contrato de gestión de servicios públicos que se regulan en su capítulo II del título II de la LCSP, relativo a la capacidad y solvencia del contratista, concretamente en los artículos 43 a 73 .

Lo que ya ha quedado aclarado respecto del agente urbanizador es que no es un contratista de obra pública, puesto que como ya dijimos en nuestro manual sobre "el agente urbanizador en el Derecho Urbanístico español" 6 , se trata de un contratista de una naturaleza mucho más compleja al encontrarse en el marco del urbanismo en el que muchos aspectos difieren de la contratación, especialmente por la existencia de propietarios afectados por la urbanización por cuanto pagarán las obras y además el agente urbanizador deberá llevar a cabo la equidistribución de sus beneficios y cargas a través del proyecto de reparcelación.

Dicha aclaración, que desafortunadamente no ha venido de España sino de la Unión Europea, tiene como origen las denuncias de una seria de ciudadanos europeos afectados por el agente urbanizador en la Comunidad Valenciana que fi-

tificar actividad urbanizadora (como función pública) con obra pública. No obstante, puede afirmarse que el contrato de concesión de obra urbanizadora es un contrato administrativo especial con regulación propia que, al descansar sobre el título competencial de urbanismo, corresponde desarrollar a las Comunidades Autónomas."

${ }^{6}$ Criado Sanchez, A.J. (2005), "El agente urbanizador en el Derecho Urbanístico Español”. Editorial Reus. 
nalmente han resultado totalmente injustificadas y que el cauce que se ha elegido para su impugnación ha sido el supuesto incumplimiento de las normas europeas de contratación. Todas esas denuncias han conllevado además de algunos informes europeos que traslucen un enorme desconocimiento del Derecho Español y a un más sorprendente desconocimiento del Derecho de otros paises miembros en relación al tratamiento del derecho de propiedad, a recursos interpuestos por la Comisión Europea ante el Tribunal de Justicia de la Unión Europea.

En este sentido cabe destacar la reciente sentencia del Tribunal de Justicia de la Unión Europea (Sala Tercera), de 26 de mayo de 2011, relativa al «Incumplimiento de Estado - Directivas 93/37/CEE y 2004/18/CE - Procedimientos de adjudicación de contratos públicos de obras - Legislación urbanística de la Comunidad Autónoma de Valencia», en el asunto C/306/08, y que tiene por objeto un recurso por incumplimiento interpuesto, con arreglo al artículo 226 CE, el 9 de julio de 2008, Comisión Europea, representada por la Sra. A. Alcover San Pedro y los Sres. D. Kukovec y M. Konstantinidis, en calidad de agentes, parte demandante, contra Reino de España, representado por el Sr. M. Muñoz Pérez, en calidad de agente, parte demandada. ${ }^{7}$

Dicha sentencia deja claro que aunque alguna de las actividades del agente urbanizador tengan relación con la realización de obras públicas, el Tribunal de Justicia de la Unión Europea ha considerado que no le son de aplicación las Directivas 93/37 y 2004/18 sobre contratos de obras públicas.

\section{EL AGENTE URBANIZADOR EN LA LEGISLACIÓN NACIO- NAL Y AUTONÓMICA}

\section{El agente urbanizador en el Texto Refundido de la Ley de Suelo de 2008.}

La filosofia del agente urbanizador hay que analizarla partiendo del derecho de iniciativa privada en la urbanización que establece el artículo 6 de la Ley de Suelo y que en definitiva supone que la producción de solares edificables es una típica función empresarial, por lo que el propietario, en modo alguno puede considerarse con un derecho exclusivo y excluyente para la conversión de su te-

\footnotetext{
${ }^{7}$ Dicha sentencia establece lo siguiente: "Por otra parte, cabe señalar que algunas de las actividades que comprenden los PAI, tanto con arreglo a la LRAU como a la LUV, según se han mencionado en el apartado anterior, parecen corresponder, por su naturaleza, a las actividades contempladas en la categoría 12 de los anexos I, parte A, de la Directiva 92/50 y II, parte A, de la Directiva 2004/18, relativas a los
} 
rreno de urbanizable a urbano, es decir, para la ejecución del planeamiento. Tan sólo, en su calidad de propietario, podrá tener algún tipo de privilegio que regulará la legislación urbanística, como por ejemplo la imposibilidad de sacar a concurso la ejecución de planeamiento durante el primer año de vigencia del planeamiento general o la adjudicación preferente del concurso si su oferta es similar a la propuesta por un concursante no propietario.

En definitiva, el TRLS 08 establece que las legislaciones autonómicas deberán regular la figura del agente urbanizador, no sólo para la ejecución material de las obras de urbanización, sino para llevar a cabo la actividad de ejecución, es decir, actuar como lo hace una junta de compensación, como responsable de la actuación.

En concreto, el artículo 6 del TRLS 08 regula el derecho a la iniciativa privada en la ejecución del planeamiento:

La legislación sobre ordenación territorial y urbanística regulará:

a)El derecho de iniciativa de los particulares, sean o no propietarios de los terrenos, en ejercicio de la libre empresa, para la actividad de ejecución de la urbanización cuando ésta no deba o no vaya a realizarse por la propia Administración competente. La habilitación a particulares, para el desarrollo de esta actividad deberá atribuirse mediante procedimiento con publicidad y concurrencia y con criterios de adjudicación que salvaguarden una adecuada participación de la comunidad en las plusvalías derivadas de las actuaciones urbanisticas, en las condiciones dispuestas por la legislación aplicable, sin perjuicio de las peculiaridades o excepciones que ésta prevea a favor de la iniciativa de los propietarios del suelo.

\section{El agente urbanizador en toda España a través de las leyes ur- banísticas de las distintas Comunidades Autónomas y caracte- rísticas comunes de su regulación.}

Cada Comunidad Autónoma ha regulado la figura del agente urbanizador de forma diferente, aunque a partir del concepto establecido en la legislación de la Comunidad Valenciana, que fue la precursora.

\footnotetext{
servicios mencionados en el artículo 1, letra a), de la Directiva 92/50 y en el artículo 1, apartado 2, letra d), de la Directiva 2004/18, respectivamente. De todo ello resulta que la Comisión no ha demostrado que el objeto principal del contrato celebrado entre el ayuntamiento y el urbanizador corresponda a contratos públicos de obras en el sentido de la Directiva 93/37 o de la Directiva 2004/18, lo que constituye una condición previa para la declaración del incumplimiento alegado."
} 
Mientras que en la Comunidad Valenciana y la de Castilla la Mancha, la ejecución del planeamiento sólo se lleva a cabo mediante el agente urbanizador y por tanto la ejecución del planeamiento requiere su adjudicación en concurso público, en el resto de Comunidades se incorpora como un sistema de ejecución más o bien como una forma de gestionar los distintos sistemas. En este último caso, la regulación y denominación por las Comunidades es muy distinta, teniendo como característica común el concurso público.

Las características principales del agente urbanizador como sistema de ejecución son las siguientes:

1) El concurso público

La ejecución de planeamiento a través del agente urbanizador requerirá la convocatoria de concurso público en el que podrán participar los propietarios y ser adjudicatarios del mismo, pudiendo la legislación urbanística establecer o no la preferencia de la oferta de los mismos sobre la del resto de aspirantes.

El artículo 120 de la Decreto Legislativo 1/2004, por el que se aprueba el Texto Refundido de la Ley de Ordenación del Territorio y de la Actividad Urbanística de Castilla la Mancha, regula de la siguiente forma el concurso público:

1. Cualquiera podrá solicitar del Alcalde que someta a información pública una alternativa técnica de Programa de Actuación Urbanizadora comprensiva de los documentos expresados en el apartado 4.1 del artículo 110.

2. El Alcalde podrá:

a)Elevar al Pleno del Ayuntamiento propuesta motivada de desestimación de la solicitud. El Pleno podrá desestimarla o, en su caso, establecer unas bases orientativas para la selección del urbanizador, acordando lo dispuesto en la siguiente letra.

b) Someter la alternativa a información pública, junto con las observaciones o alternativas que, en su caso, estime convenientes. Durante la información pública se admitirán tanto alegaciones como alternativas técnicas a la expuesta al público y, tras la conclusión de la información pública, quienes tengan interés por competir y ser seleccionados como adjudicatarios del correspondiente Programa de Actuación Urbanística, podrán presentar proposiciones jurídico-económicas.

3. Las alternativas técnicas se presentarán a la vista, con la documentación expresada en el apartado 4.1 del artículo 110, acompañada, en su caso, de proyectos complementarios. Las proposiciones jurídico-económicas y la propuesta de convenio se presentarán en plica cerrada con la documentación prevista en los apartados 4.2 y 4.3 del número 4 del artículo 110. 
4. La información pública se anunciará mediante edicto publicado en el Diario Oficial de Castilla-La Mancha y, posterior o simultáneamente, en uno de los periódicos de mayor difusión en la localidad. (...)

5. Durante todo el procedimiento podrán ser objeto de pública consulta, en el Municipio, las alegaciones y alternativas técnicas que se vayan presentando ante éste. El Alcalde y el Secretario de la Corporación o funcionario a quien corresponda, deberán dar inmediato conocimiento de dichas alternativas al órgano municipal correspondiente a medida que las mismas sean presentadas. Se podrán presentar alternativas técnicas y alegaciones durante veinte días contados desde la última publicación del edicto. Las proposiciones jurídico-económicas se presentarán durante los diez días siguientes al vencimiento del plazo anterior. (...)

6. El acto de apertura de plicas se celebrará en la siguiente fecha hábil a la conclusión del último plazo de informa ción pública, de su desarrollo y resultado se levantará acta, bajo fe pública y ante dos testigos. El contenido de las plicas será objeto de información pública durante los veinte días siguientes al de apertura de plicas. Vencido dicho plazo, los competidores podrán acordar la unión de sus proposiciones.

\section{2) El programa}

El programa es el documento en el que se contiene tanto el planeamiento de desarrollo como, los elementos jurídicos y económicos de la propuesta, como incluso un anteproyecto de urbanización. Todo ello en un único trámite y documento, incluyendo toda la documentación necesaria para la ejecución de planeamiento.

El artículo 125 de la Ley 16/2005, de 30 de diciembre, Urbanística de la Comunidad Valenciana establece la siguiente documentación integrante de los programa de actuación integrada:

1. La Alternativa Técnica y la Proposición Furídico-económica son los dos documentos integrantes de los Programas para el desarrollo de las Actuaciones Integradas. 2. La alternativa técnica es el documento que identifica el ámbito de suelo objeto de transformación, establece si procede la ordenación detallada o estructural a desarrollar mediante el programa y incluye el proyecto de urbanización así como su correcta integración en la ciudad o el territorio. 3. La Proposición Furídico-económica es el documento del Programa que determina las condiciones jurídicas, económicas y financieras de su ejecución.(...) 6. Los programas preverán la edificación de los solares resultantes en un año contador a partir de la recepción municipal de las obras de urbanización, pudiéndose ampliar de manera justificada en las condiciones de absorción por el mercado inmobiliario hasta un plazo máximo de cuatro años, determinándose la secuencia y prioridad de la ejecución, en dos bases bianuales. 
3) El convenio entre la administración y el agente urbanizador

El agente urbanizador adjudicatario suscribirá un convenio urbanístico con la administración para confirmar todos sus compromisos, especialmente los posibles acuerdos con los propietarios, así como las penalizaciones ante sus incumplimientos.

El artículo 135.10 de la Ley 15/2001, de 14 de diciembre, del Suelo y Ordenación Territorial de Extremadura regula el convenio con el agente urbanizador adjudicatario de la siguiente forma:

La adjudicación de la ejecución del Programa de Ejecución se formalizará mediante convenio urbanístico a suscribir, de una parte, por el agente urbanizador en el sistema de concertación o por la agrupación de interés urbanístico en el de compensación y, de otro, tanto por la Administración actuante como, en su caso, por aquellas otras que hubieran asumido compromisos en dicha ejecución. En él se harán constar las condiciones, los compromisos y los plazos para la ejecución del Programa, las garantías que el agente urbanizador presta para asegurar su cumplimiento y las penalizaciones a que se somete por incumplimiento.

En definitiva, lo importante de la ejecución del planeamiento mediante agente urbanizador es que se generaliza por el concurso, se elimina la exclusividad del propietario para la ejecución del planeamiento, algo que ha sido confirmado en el artículo 6 TRLS 08, así como se agiliza la tramitación urbanística con el programa como documento que incluye el planeamiento preciso, así como aspectos jurídicos, económicos e incluso de urbanización, convirtiéndose la ejecución de planeamiento más en una gestión de planeamiento.

\section{ASPECTOS GENERALES DEL AGENTE URBANIZADOR EN LA MODIFICACIÓN DE LA LOUA}

\section{La exposición de motivos establece que las obras de urbani- zación son obras públicas.}

El carácter público de las obras de urbanización ha sido objeto de un amplio debate doctrinal a raiz de la sentencia de 21 de julio de 2001 del TJCE sobre el Teatro la Scala de Milán ${ }^{8}$. La exposición de motivos de la Ley que modifica la LOUA clarifica su carácter público.

\footnotetext{
${ }^{8}$ El fallo del TJCE fue el siguiente: "La Directiva 93/37/CEE del Consejo de Europa, de 14 de junio de 1.993, sobre la coordinación de los procedimientos de adjudicación de los contratos públicos de obras,
} 
En concreto, lo establece de la siguiente forma en su apartado tercero:

De conformidad con la legislación estatal, la ejecución urbanística tendrá lugar siempre bajo control público, clarificándose el carácter público de las obras de urbanización, de manera que las ejecutará la Administración, mediante financiación propia, de las personas propietarias, junta de compensación, o de un agente urbanizador.

Establecer y aclarar que las obras de urbanización son obras públicas y además establecer que se aclara "de conformidad con la legislación estatal" no puede sino derivar en que a dichas obras le sea de aplicación las normas de la contratación del sector público, especialmente en relación al contrato de obra pública para las de urbanización. De hecho, se establecía dicha aplicación de forma expresa en el Anteproyecto de Ley no en la exposición de motivos ${ }^{9}$, sino también al definir "la empresa constructora" como la empresa encargada de la ejecución material sometida a la normativa de la contratación del sector público $^{10}$. Dichas referencias expresas se eliminaron del Proyecto de Ley que tuvo tramitación parlamentaria y así quedó finalmente en la Ley aprobada. La intención de dicha eliminación parece que ha sido la de evitar la mayor carga de trabajo que la tramitación de los concursos para la adjudicación de las obras de urbanización supone para los ayuntamientos, que atraviesan en toda España una delicadísima situación económica y por tanto una gran escasez de medios económicos y materiales.

se opone a una legislación nacional en materia de urbanismo que permite, apartándose de los procedimientos previstos por esta Directiva, la realización directa por el titular de una licencia urbanística o de un plan de urbanización aprobado de una obra de urbanización, con imputación de la totalidad o parte de la obra a cuenta de la contribución adecuada por la concesión de la licencia, cuando el valor de dicha obra sea igual o superior al umbral fijado por dicha Directiva».

${ }^{9}$ El texto completo del párrafo citado de la Exposición de Motivos del anteproyecto de Ley era el siguiente, la parte en cursiva se eliminó del Proyecto de Ley que se tramitó en el Parlamento autonómico: "De conformidad con la legislación estatal, la ejecución urbanística tendrá lugar siempre bajo control público, clarificándose el carácter público de las obras de urbanización, de manera que las ejecutará la Administración, mediante financiación propia, de las personas propietarias, junta de compensación, o de un agente urbanizador. Así, la presente modificación hace hincapié en el carácter público de la obra de urbanización, imponiendo el respeto a las garantías que en materia de contratación del sector público derivan de la normativa de la Unión Europea, garantías que se proyectan tanto sobre la administración como sobre la junta de compensación o el agente urbanizado y que inspiran parte de las previsiones del texto refundido de la Ley de Suelo."

${ }^{10}$ En el Anteproyecto de Ley, se definía la "empresa constructora" de la siguiente forma: "A los efectos de esta Ley, se entiende por empresa constructora aquella persona física o jurídica encargada de la ejecución material de las obras de urbanización. Las relaciones jurídicas de la empresa constructora con el agente urbanizador o la junta de compensación se someterán a la normativa de contratación del sector público. La empresa constructora quedará obligada sólo ante el agente urbanizador que asumirá, por tanto, la total responsabilidad de la ejecución de la actuación frente de la Administración" 
La cuestión interpretativa que se plantea es si es de aplicación a las obras de urbanización que contratan las juntas de compensación o el agente urbanizador las normas de la contratación del sector público, especialmente con la eliminación de las referencias expresas a dichas normas. Nuestra opinión es la misma que antes de la aclaración de la Ley 2/2012 de que las obras de urbanización son obras públicas, y es que si es de aplicación dichas normas para la reforma de una plaza pública de un coste de cien mil euros, con más motivo debe ser de aplicación para las obras de una nueva parte de la ciudad que incluirá calles, aceras, alumbrado público, parques públicos y cuyo presupuesto normalmente no es inferior a un millón de euros.

Sin embargo, dado que no se establece de forma expresa la obligatoriedad de las juntas de compensación o del agente urbanizador de contratar las obras de urbanización, la jurisprudencia del Tribunal Superior de Justicia no parece que vaya a variar, dado que le resulta indiferente el carácter público de las obras de urbanización, si el órgano contratante es una entidad de carácter privado, aunque sea entidad urbanística colaboradora, como es una junta de compensación. Así lo entiende en sentencias como la de 8 de septiembre de 2005, en la que se establece que la junta de compensación puede contratar las obras de urbanización bajo las normas del derecho público o privado, así como que, además, la contratación es un aspecto que queda fuera de la esfera de control de la administración actuante, es decir, del Ayuntamiento ${ }^{11}$.

\footnotetext{
11 Así lo considera el TSJ de Andalucía, en sentencias como la de 8 de septiembre de 2005: "La evolución legislativa del sistema de compensación, que culmina en lo que ahora interesa, en el art ${ }^{\circ} 176.2$ del $R G U$, vino a reconocer a las Juntas de Compensación la total y completa libertad para contratar las obras de urbanización, lo que resultaba coherente con la naturaleza de estas como organizaciones de base privada en la que está muy presente el derecho de propiedad, y cuya naturaleza administrativa sólo adquiere relieve en el ámbito de las funciones públicas que legalmente se les atribuye. A pesar de ello, existen pronunciamientos jurisprudenciales, ver por ejemplo la sentencia del TS de 24 de mayo de 1994 -por cierto que resuelve un caso parecido al que nos ocupa, en el que se dicta una sentencia de inadmisibilidad por incompetencia de jurisdicción y trata expresamente el caso de no interposición del recurso de alzada ante el Ayuntamiento--, en los que ante la lógica de la propiedad, superpone la lógica de la obra pública, por lo que es preciso la contratación administrativa, por lo que en caso de contratar las obras de urbanización con terceros debe observarse las reglas de publicidad y libre concurrencia prevista tanto en la Directiva 93/37, como en el Real Decreto Legislativo 2/00. Mientras que en otras Comunidades Autónomas se ha impuesto para ciertos casos de contratación de obra urbanizadora la obligatoriedad de la contratación administrativa, en el caso de nuestra Comunidad Autónoma, la Ley 7/02, en el sistema de compensación no se pronuncia al respecto, si por ejemplo en el sistema de cooperación, art ${ }^{\circ} 123$. En principio, pues cabe la libertad de contratación, tanto sometida al derecho privado como público, - sin perjuicio de la doctrina sentada por la sentencia del Tribunal de Justicia de la Unión Europea, del 12 de julio de 2001, caso Scala de Milán, aunque a la conclusión a la que llegamos resulta indiferente que exista libertad de contratación de las obras de urbanización con los terceros o deba someterse a los cauces de la contratación administrativa-; mas en el caso de que se opte por esta, por así disponerlo las Bases de Actuación, bien me-
} 


\section{La eliminación del derecho de adjudicación preferente de los propietarios en los concursos para la adjudicación de la urba- nización.}

La legislación de suelo nacional regula los derechos y deberes básicos del propietarios, regulándose por la legislación urbanística los derechos y deberes complementarios, entre los cuales se encuentra el derecho de adjudicación preferente en los concursos para la adjudicación de la urbanización.

Dicho derecho preferente se regulaba en el artículo 50 de la LOUA, que establecía en su anterior redacción en relación al contenido urbanístico del derecho de propiedad del suelo, lo siguiente:

Forman parte del contenido urbanístico del derecho de propiedad del suelo, sin perjuicio
del régimen que le sea de aplicación a éste por razón de su clasificación, los siguientes
derechos: D) Cuando se trate de terrenos clasificados como suelo urbanizable sectoriza-
do u ordenado para los que la Administración actuante no opte por la ejecución públi-
ca directa del planeamiento correspondiente, los derechos previstos en el apartado A)

diante la aplicación de los actos separables, su régimen jurídico queda sometido a las disposiciones contenidas en el Real Decreto Legislativo 2/00. Ha de convenirse, pues, que en principio la Junta de Compensación podría legítima y legalmente contratar las obras de urbanización con cualquier tercero y sometido a las reglas de la contratación privada, es llano, pues que en este aspecto no se dilucida ni se pone en cuestión el ámbito material que exige que la Administración asuma la dirección y el control del proceso de ejecución, fiscalizando que su desarrollo se ajuste a la legalidad urbanística y se respetan los principios y reglas exigibles; esto es, la contratación de las obras de urbanización quedan al margen del ámbito competencial propio de la Administración tutelante. Realizada las anteriores distinciones, dado que en caso presente no se discute que la contratación de las obras de urbanización se ha realizado bajo los criterios de publicidad y concurrencia, sometida a al ordenamiento administrativo en materia de contratación, el caso resulta exactamente igual a cualquier supuesto en los que el régimen organizativo y estructural administrativo determinante del sistema impugnatorio, se altera por imponer la $L C A P$, $a r t^{\circ} 59$ y 60 , un régimen impugnatorio peculiar en la materia de contratación. Por tanto, insistimos igual que sucede en cualquier otro régimen o ámbito material que establece el sistema de recurso, tan especial o específico en la materia como el que establece el art ${ }^{\circ} 135.5$ de la Ley 7/02, en referencia al sistema de recurso de los acuerdos de las Juntas de Compensación, parafraseando a la sentencia del TS de 24 de mayo de 1994 , podemos decir que no toda decisión de esta tenga que ser susceptible de recurso de alzada ante la Administración tutelante, sino tan sólo aquella que afecte a la actividad administrativa desde la perspectiva urbanística sobre la que se articula sus facultades y ámbito de competencia, pues la razón de ser de dicha fiscalización no descansa tanto sobre la Entidad tutelada como sobre la actividad que aquella realiza, de suerte que cuando la misma incida en la gestión urbanística debe entrar en juego la Administración que ostenta la tutela, mas cuando, como ocurre en el presente caso, de contratación de las obras de urbanización, de libre contratación, pero sometida a la contratación administrativa, la actividad de que se trata es propia de la contratación administrativa, sometida a sus reglas, entre las que se encuentra el sistema impugnatorio de los actos del órgano contratante, y que en la perspectiva que en este interesa resulta ajena a la Administración, por lo que ningún sentido tiene su intervención. 
comprenden el de iniciativa y promoción de su transformación mediante la urbanización, que incluyen los siguientes: a) Competir, en la forma determinada en esta Ley y en unión con los restantes propietarios afectados cuando ésta así lo exija, por la adjudicación de la urbanización en régimen de gestión indirecta de la actuación y con derecho de preferencia sobre cualquiera otra oferta equivalente formulada por no propietario.

Es decir, que en la anterior regulación se establecía el derecho preferente de la oferta del propietario por otra equivalente presentada por un no propietario para la adjudicación de la urbanización.

La actual regulación del artículo 50 D) de la LOUA es bien distinta, dado que elimina el derecho de adjudicación preferente de los propietarios:

"D) Cuando se trate de terrenos clasificados como suelo urbanizable sectorizado u ordenado para los que la Administración actuante no opte por la ejecución pública directa del planeamiento correspondiente, los derechos previstos en el apartado A) comprenden el de iniciativa y promoción de su transformación mediante la urbanización, que incluyen los siguientes: a) Competir, en la forma determinada en esta Ley, por la adjudicación de la urbanización en régimen de gestión indirecta de la actuación. b) Con independencia del ejercicio o no del derecho anterior, participar, en la forma y condiciones determinadas en esta Ley, en el sistema urbanístico determinado para la ejecución de la urbanización, o en la gestión indirecta de la actuación en condiciones libremente acordadas con el adjudicatario de la misma. c) Ceder los terrenos voluntariamente por su valor o, en todo caso, percibir el correspondiente justiprecio, en el caso de no participar en la ejecución de la urbanización.”

\section{La nueva definición de agente urbanizador, agente construc- tor y urbanizador.}

Si bien la definición de agente urbanizador venía siendo ajustada su regulación, la Ley 2/2012 amplia dicha definición en consonancia con la mejora de su regulación.

La nueva definición del agente urbanizador se establece en el artículo 97 bis de la LOUA, que lo define de la siguiente forma:

\section{"Artículo 97 bis. Agente urbanizador.}

1. El agente urbanizador es la persona legitimada por la Administración actuante para participar, a su riesgo y ventura, en los sistemas de actuación, asumiendo la responsabilidad de su ejecución frente a la Administración actuante y aportando su actividad 
empresarial de promoción urbanística. 2. La condición de agente urbanizador puede ser asumida por cualquier persona fisica o jurídica, pública o privada, propietaria o no del suelo. 3. El agente urbanizador obtiene la legitimación para intervenir en la ejecución urbanística tras su selección en pública concurrencia por la Administración actuante y la suscripción del convenio urbanístico regulador de la actuación urbanizadora conforme a lo dispuesto en esta Ley y supletoriamente en la legislación de contratación del sector público para el contrato de gestión de servicios públicos. 4. Cuando el agente urbanizador reúna los requisitos de capacidad para la ejecución por él mismo de las obras de urbanización y dichos requisitos y condiciones se hubieran recogido en el procedimiento para su selección, no será precisa la convocatoria de una nueva licitación pública para la ejecución de las obras."

Entendemos que se trata de una buena definición y que coincide en líneas generales con la definición de agente urbanizador que hemos realizado en el epígrafe segundo de este artículo. Sin embargo, a nuestro juicio, adolece de un grave error el apartado tercero del artículo 97 bis al establecer la aplicación supletoria de la legislación de contratos del sector público en relación al contrato de gestión de servicios públicos, cuyo objeto difiere de forma sustancial con el objeto del contrato que suscribe el agente urbanizador. En todo caso, dicha referencia a la aplicación supletoria de la legislación de contratos del sector público debería ser genérica.

Además, el nuevo apartado segundo del 130.1.d) de la LOUA hace igualmente referencia a la aplicabilidad de la regulación del contrato de gestión de servicios públicos en cuanto a los requisitos del agente urbanizador:

El agente urbanizador deberá reunir los requisitos exigidos en esta Ley y, supletoriamente, por la legislación reguladora de la contratación del sector público para el contrato de gestión de servicio público.

En este apartado, consideramos que la referencia a los "requisitos" debería ser no supletoria sino directa a las normas de la contratación del sector público, con una redacción similar a ésta:

El agente urbanizador deberá reunir los requisitos exigidos en esta Ley, así como los generales establecidos para los contratantes por la legislación reguladora de la contratación del sector público.

Dicha redacción derivaría en que al agente urbanizador le fuese de aplicación los requisitos generales de los contratistas de la LCSP, que se regulan en su capítulo II del título II, relativo a la capacidad y solvencia del empresario, 
concretamente en los artículo 43 a 73, y que redundaría en una garantía en la calidad de la ejecución de las obras de urbanización y de solvencia de las empresas contratistas.

Y de no haberse hecho una referencia de aplicación directa, al menos supletoria con carácter general, pero ningún sentido tiene la referencia al contrato de gestión de servicios públicos, que se regula en los artículos 251 a 265 de la LCSP y se define en su artículo 8.1 de la siguiente forma:

El contrato de gestión de servicios públicos es aquél en cuya virtud una Administración Pública o una Mutua de Accidentes de Trabajo y Enfermedades Profesionales de la Seguridad Social, encomienda a una persona, natural o jurídica, la gestión de un servicio cuya prestación ha sido asumida como propia de su competencia por la Administración o Mutua encomendante.

Asimismo el 251 de la LCSP se refiere al ámbito de dicho contrato:

1. La Administración podrá gestionar indirectamente, mediante contrato, los servicios de su competencia, siempre que sean susceptibles de explotación por particulares. En ningún caso podrán prestarse por gestión indirecta los servicios que impliquen ejercicio de la autoridad inherente a los poderes públicos. 2. El contrato expresará con claridad el ámbito de la gestión, tanto en el orden funcional, como en el territorial.

Por tanto, por razón del objeto, la referencia al contrato de gestión de servicios públicos es totalmente errónea. Sin embargo, aún más errónea es la referencia a este contrato en cuanto a los requisitos del agente urbanizador (artículo 130.1.d) de la LOUA), dado que en la regulación de este contrato no se incluye ningún requisito específico del contratista, únicamente se regulan aspectos como las modalidades de contratación, duración del contrato, obligaciones generales del contratista, así como aspectos económicos y del objeto del contrato, pero en ningún caso subjetivos del contratista.

$\mathrm{El}$ apartado cuarto del artículo 97 bis establece para el agente urbanizador una exigencia adicional de los requisitos de capacidad al agente urbanizador cuando su iniciativa plantee la ejecución de las obras de urbanización. El objeto de esta referencia, en realidad, es aclarar que los requisitos de capacidad serán los establecidos en las bases del concurso establecidas por la administración actuante, normalmente el Ayuntamiento, pero no los requisitos generales de la legislación de contratos del sector público, es decir, los artículos 43 a 73 de la Ley de Contratos del Sector público relativos a capacidad, solvencia y clasificación de los contratantes con el sector público, que es lo que consideramos debería ser aplicable. 
Si bien se puede tener alguna justificación intentar eludir el procedimiento de contratación establecido para la legislación de de contratos del sector público para las obras de urbanización para evitar esa carga adicional de trabajo a los ayuntamientos, no resulta razonable que no sean de aplicación directa los requisitos de los contratantes con el sector público al agente urbanizador, especialmente cuando se afirma en la exposición de motivos que las obras de urbanización son obras públicas. Y ello puesto que los requisitos de los contratantes son una garantía para la correcta ejecución de las obras de urbanización, que son sin duda de las obras públicas de más importancia desde el punto de vista económico y social para una ciudad.

En relación a la definición de la empresa urbanizadora y empresa constructora, se establece en el nuevo artículo artículo 97 ter de la LOUA:

\section{“Artículo 97 ter. La empresa urbanizadora y la empresa cons- tructora.}

1. Podrá coadyuvar con las personas propietarias a quienes corresponda la iniciativa del sistema de actuación por compensación una empresa urbanizadora que asuma la financiación de la actuación y, en su caso, preste especialización profesional a la gestión urbanística de acuerdo con las condiciones libremente pactadas entre ambas partes. Los gastos asumidos por la empresa urbanizadora necesarios para la ejecución y desarrollo de la actuación podrán ser retribuidos, total o parcialmente, con parcelas o solares a materializar en el proyecto de reparcelación. La colaboración de empresa urbanizadora no exime a las personas propietarias, o en su caso a la Junta de Compensación, de la directa responsabilidad asumida con la Administración actuante en la ejecución del sistema de actuación. 2. A los efectos de esta Ley, se entiende por empresa constructora aquella persona fisica o jurídica encargada de la ejecución material de las obras de urbanización. Cuando la empresa constructora sea contratada por un agente urbanizador, éste asumirá la total responsabilidad de la ejecución de la actuación frente a la Administración, sin perjuicio de las relaciones jurídicas con la empresa constructora."

El objetivo de este artículo tenía especial sentido en el Anteproyecto de Ley de modificación de la LOUA en el que se establecía la necesidad de contratación de las obras de urbanización mediante el procedimiento de la LCSP para su adjudicación a la "empresa constructora", diferenciándola de la "empresa urbanizadora", que no se sometía a dicho procedimiento sino al acuerdo con los propietarios para la realización de la obra a cambio de de solares. Algo que por cierto parecía bastante incongruente y de difícil justificación, dado que nada impediría establecer en un concurso público el pago en dinero o en especie del precio del contrato ${ }^{12}$. 
Con la actual regulación, habría bastado con haber regulado únicamente "la empresa urbanizadora" y establecido la posibilidad de realización de las obras a cambio de abono total o parcial en solares, dado que no tiene demasiado sentido su distinción de la "empresa constructora".

En relación a la "empresa constructora", se trata del mismo término que utiliza la Ley Urbanístiva Valenciana (LOUV) en su artículo 120, que define al "empresario constructor" como el "responsable de ejecutar el proyecto de urbanización aprobado por la administración".

Entendemos que se trata de un término incorrecto, dado que dicha empresa no lleva a cabo obras de construcción sino de urbanización, por lo que debería utilizarse el término "contratista de obras de urbanización" o bien simplemente "contratista", que es la terminología general utilizada por la Ley de Contratos del Sector Público.

En definitiva, el artículo 97 ter debería haber definido únicamente al contratista de las obras de urbanización y haber incluido que el precio de la obra se podría abonar el dinero o en su equivalente en terrenos edificables, algo además perfectamente ajustado a la Ley de Contratos del Sector Público.

\section{LA NUEVA REGULACIÓN DEL AGENTE URBANIZADOR EN EL SISTEMA DE COMPENSACIÓN}

\section{Consideraciones generales.}

La regulación de la LOUA en relación al agente urbanizador se ha caracterizado por su inclusión en los sistemas tradicionales de ejecución de planeamiento como una forma más de gestión de los mismos, a diferencia de la mayoría de Comunidades que lo han introducido como un nuevo sistema de ejecución.

Las dos carencias más importantes de esta regulación han sido, por un lado, la remisión a un desarrollo reglamentario en los sistemas de expropiación y co-

\footnotetext{
${ }^{12} \mathrm{El}$ artículo 75.1 de la LCSP en relación al precio establece la posibilidad del pago en especie: "En los contratos del sector público, la retribución del contratista consistirá en un precio cierto que deberá expresarse en euros, sin perjuicio de que su pago pueda hacerse mediante la entrega de otras contraprestaciones en los casos en que ésta u otras Leyes así lo prevean. Los órganos de contratación cuidarán de que el precio sea adecuado para el efectivo cumplimiento del contrato mediante la correcta estimación de su importe, atendiendo al precio general de mercado, en el momento de fijar el presupuesto de licitación y la aplicación, en su caso, de las normas sobre ofertas con valores anormales o desproporcionados."
} 
operación. Por otro, el no haber establecido al agente urbanizador como responsable del sistema de compensación al tener que formar parte de la junta de compensación con el resto de propietarios.

Desafortunadamente, la Ley 2/2012 no aborda el primer problema y por tanto el agente urbanizador sigue sin ser de aplicación en los sistema de expropiación y cooperación. Sin embargo, si que se aborda la segunda carencia del sistema de compensación de una forma bastante atractiva para los empresarios al introducir además la garantía del reembolso de la inversión en caso de adjudicación de la iniciativa a los propietarios.

Quizás la crítica más importante que se pueda hacer a la nueva regulación del agente urbanizador es no haberla regulado como un sistema nuevo, porque de hecho, al no haber junta de compensación, prácticamente es un sistema distinto del de compensación, o al menos haber regulado en un artículo más, un artículo 134 bis por ejemplo, algunas particularidades de la ejecución de planeamiento con el agente urbanizador, como es la tramitación del proyecto de reparcelación, la aprobación de las cuotas de urbanización o la posibilidad de constitución por los propietarios de una entidad urbanística colaboradora con fines de control y fiscalización.

\section{La iniciativa del agente urbanizador para el establecimiento del sistema de compensación.}

\subsection{Requisitos de la iniciativa.}

a) La elección del sistema de actuación por compensación y las bases orientativas para el calculo de los gastos de urbanización

La nueva regulación de la iniciativa del sistema de compensación introduce como primer requisito adicional, además de la elección del sistema de actuación por compensación, las bases orientativas para su ejecución relativas como mínimo a calidades, plazos y diseño urbano, con objeto de poder calcular los gastos de urbanización.

A ello se refiere el artículo 130.1.d que a su vez se remite al artículo 96.2 de la LOUA que regula la excepción para la ejecución del planeamiento sin la aprobación del planeamiento preciso:

"2. Sin perjuicio de lo dispuesto en el apartado anterior, en el suelo urbanizable sectorizado y urbano no consolidado, a los efectos del establecimiento del sistema de actua- 
ción, podrán efectuarse los actos jurídicos de ejecución necesarios, siempre que la unidad de ejecución haya sido delimitada y se haya procedido a la elección del sistema de actuación, que deberá incluir las bases orientativas para su ejecución relativas, al menos, a calidades, plazos y el diseño urbano, con el alcance necesario para calcular los gastos de urbanización imputables a la actuación."

El objeto de esta referencia es, en primer lugar, para que aún sin planeamiento de desarrollo, se pueda presentar la iniciativa del agente urbanizador, dado que normalmente será quien lo redacte y financie. En segundo lugar se pretende que con estas bases de diseño urbano, se pueda establecer una estimación aproximada de los costes de urbanización, dado que serán un elemento capital de las distintas ofertas que se presenten en plica cerrada para la adjudicación del concurso de agente urbanizador y una garantía sobre todo para los propietarios que tengan que afrontarlas.

b) El transcurso de nueve meses sin que se haya presentado ninguna otra iniciativa

El segundo requisito para presentar la iniciativa por el agente urbanizador es igualmente una novedad, dado que deben transcurrir nueve meses desde la elección del sistema de compensación y las bases orientativas para poder estimar los costes de urbanización o aprobación del planeamiento de desarrollo, sin que se haya presentado ninguna de las otra iniciativas posibles por los propietarios incluidos en el ámbito de la unidad de ejecución.

Se trata de una novedad dado que hasta la Ley 2/2012, el agente urbanizador podía presentar su iniciativa el cualquier momento, aunque en realidad, ello no suponía demasiado problema para los propietarios dado que en cualquier momento podían paralizarla mediante el acuerdo de la mayoría.

Este requisito es una importante garantía para que los propietarios que quieran ejecutar su unidad de ejecución, puedan hacerlo sin tener que competir con la iniciativa de un agente urbanizador. Se trata además de una garantía que a efectos del interés general, es mejor que el derecho de adjudicación preferente que en muchos casos puede utilizarse únicamente para impedir la iniciativa de un agente urbanizador, aunque se haya producido muchos años después del incumplimiento de los plazos de ejecución.

No es sin embargo la única garantía de los propietarios, que evidentemente no encajaría con la legislación de contratos del sector público, dado que a nivel procedimental, se establece otra garantía que se verá más adelante. 


\subsection{El contenido de la iniciativa.}

Ya dijimos en la introducción que la nueva regulación del agente urbanizador es bastante continuista y que su objetivo ha sido introducir leves mejoras. De ahí que el contenido de la iniciativa del agente urbanizador no difiera demasiado de la anterior regulación.

El contenido se regula en el artículo 130 de la LOUA, con la primera novedad de que se realiza una distinción entre la iniciativa de los propietarios y la del agente urbanizador. Concretamente en su apartado 5 y 6 se regulan los requisitos específicos del contenido de la iniciativa del agente urbanizador

“a) Identificación de la persona ofertante y acreditación del cumplimiento de los requisitos exigibles en virtud de lo establecido en el segundo párrafo del apartado 1.d) de este artículo.

b) Fustificación de su propia iniciativa para desarrollar la actuación urbanizadora, en cumplimiento de las previsiones y directrices del planeamiento vigente.

c) Compromiso de contratar, salvo en el caso previsto en el apartado 4 del artículo 97 bis, las obras de urbanización a empresa constructora siguiendo los principios de publicidad y concurrencia.

d) La previsión de incorporación de las personas propietarias mediante la aportación de sus fincas originarias y con opción entre el abono en metálico de la parte de los costes de urbanización que les sean imputables y la cesión de terrenos edificables de valor equivalente a dicha parte de los costes.

e) La previsión de que las personas propietarias que no se incorporen a la iniciativa puedan solicitar la expropiación de sus terrenos.

f) La previsión de que las personas propietarias que no opten por alguna de las alternativas anteriores quedarán sujetas a reparcelación forzosa.

g) Oferta de adquisición del suelo de las personas propietarias que, en su caso, no hayan suscrito la iniciativa de los terrenos de su titularidad afectados por la actuación.

h) Presupuesto de gastos totales de urbanización, separando el coste de contrata de ejecución de las obras de urbanización del resto de gastos, y oferta de compensación de los costes de urbanización mediante cesión de terrenos edificables de valor equivalente, que se aplicará igualmente a las personas propietarias que puedan quedar sujetas a reparcelación forzosa.

i) Garantías económicas para el desarrollo de los trabajos, que no podrán ser inferiores en cuantía al siete por ciento de los costes de urbanización y de otros que sean objeto de la actividad a desarrollar.

j) Fustificación de la solvencia económica, financiera y técnica de la iniciativa, así como de las personas propietarias promotoras que se adhieran a la misma.

6. A la documentación señalada en el apartado anterior, podrá añadirse para su trami- 
tación simultánea la ordenación detallada suficiente para ejecutar la urbanización y, en su caso, el proyecto de urbanización"

Del contenido de la iniciativa, en primer lugar merece un comentario el apartado c) relativo al compromiso de contratación de las obras de urbanización con la "empresa constructora" bajo los principios de publicidad y concurrencia siempre que no reúna los requisitos necesarios el agente urbanizador. Entendemos que este apartado debería establecer, o bien el compromiso de contratación o bien la acreditación de la capacidad para afrontar las obras de urbanización, dado que desafortunadamente en este apartado no se remite a los requisitos de la legislación de contratos del sector público. Entre tales requisitos podrían considerarse acreditar medios materiales, personales y sobre todo experiencia. Consideramos que hubiese sido más acertada la siguiente redacción de este apartado:

c) Compromiso de contratar las obras de urbanización a empresa constructora siguiendo los principios de publicidad y concurrencia o acreditación de la capacidad del agente urbanizador para su ejecución.

En relación a los principios de publicidad y concurrencia para la contratación de la "empresa constructora", aunque ya hemos afirmado que lo procedente legalmente es que el procedimiento se sujetase a lo establecido en la legislación de contratación pública, parece poco razonable que no requiera la contratación por los propietarios de las obras de urbanización los principios de publicidad y concurrencia y por su puesto tampoco requiera tales principios el acuerdo con "la empresa urbanizadora".

En relación a lo que deba entenderse por tales principios, el de publicidad requerirá como mínimo la convocatoria en el boletín oficial de la provincia de la contratación de las obras de urbanización o en un diario de importante difusión provincial, así como la posibilidad de que haya una efectiva concurrencia estableciendo un plazo razonable para la presentación de ofertas así como una bases objetivas para su elección.

Lo que parecería razonable es que el acuerdo de adjudicación de las obras de urbanización fuese de la administración actuante y la tramitación se sometiese a las normas de la contratación pública, con objeto de que dicho acuerdo pudiese ser impugnado en vía administrativa y en su caso judicial por los particulares que deben abonar los costes de urbanización. Sin embargo, dado que el TSJ de Andalucía considera en la sentencia de 8 de septiembre de 2005 anteriormente citada que la contratación de dicha obra de urbanización es una 
cuestión privada y fuera del control municipal, será bastante excepcional el supuesto en el que sea el Ayuntamiento quien acuerde dicha contratación y lo someta a las normas de la contratación del sector público.

Por ello, la relación jurídica entre el agente urbanizador y la "empresa constructora" se sujetará a lo establecido en el contrato que firmen ambas partes y a las normas del Derecho Privado, especialmente a la Ley de Ordenación de la Edificación y al Código Civil.

El segundo elemento que merece la pena comentar, por ser de las aportaciones de la Ley 2/2012, es el presupuesto de gastos de urbanización, separando los gastos de ejecución material del resto, así como la oferta de compensación de costes de urbanización con terrenos edificables. El objeto de este apartado es el conocimiento de la propuesta de costes de gestión y de beneficio empresarial para poder determinar cual de las ofertas de la mejor desde la perspectiva del precio, algo que más o menos parece razonable.

Se incluye en este apartado la oferta de compensación de gastos de urbanización con terrenos edificables, que además será aplicable a los propietarios sujetos a reparcelación forzosa. Se trata de este de un elemento capital, regulado de la misma manera para la iniciativa de los propietarios para la constitución de la junta de compensación, susceptible de abusos hacia los propietarios minoritarios sin recursos económicos. Debería haberse aprovechado para establecer una regulación algo más clara, dadas las consecuencias que de ella derivan, especialmente para los propietarios sujetos a la reparcelación forzosa, dado que como oferta, no está sujeta a una limitación más que a la concurrencia de otras ofertas con mejores condiciones. En este sentido, durante el plazo de información pública, no hay posibilidad de alegación por los propietarios afectados a la cantidad para compensar los gastos de urbanización puesto que es una oferta, una mera opción al pago en dinero de los gastos de urbanización.

Lo más importante de la oferta es que sea clara, para lo que el propietario debe conocer como se valora la unidad de aprovechamiento (terrenos edificables) a efectos de su compensación, dado que con cierta frecuencia las ofertas de compensación que realizan las juntas de compensación se refieren erróneamente a suelo bruto o terrenos aportados, cuyo valor es evidentemente menor y además no se corresponde con los "terrenos edificables" que dice nuestra legislación urbanística. Por ello, la siguiente redacción parecería más clara y garantista para los propietarios: 
h) Presupuesto de gastos totales de urbanización, separando el coste de contrata de ejecución material de las obras de urbanización de los gastos de gestión y del beneficio empresarial, y oferta de compensación de los costes de urbanización mediante cesión de terrenos edificables de valor equivalente, que se aplicará igualmente a las personas propietarias que puedan quedar sujetas a reparcelación forzosa. La oferta incluirá un valor en euros de la unidad de aprovechamiento a efectos de su compensación con los gastos de urbanización.

El tercer aspecto que merece comentar de la iniciativa es la acertada inclusión de los propietarios que se adhieran a la iniciativa presentada, es decir, aquellos con los que se haya llegado a acuerdos por el agente urbanizador con carácter previo a la presentación de la iniciativa, respecto a los requisitos de solvencia económica, financiera técnica. Y ello puesto que aquellos propietarios que pretendan asumir la iniciativa de alguna es razonable que tengan que acreditar su solvencia de cara a hacer frente a los gastos de urbanización y otros costes del sistema.

\section{El procedimiento para la adjudicación de la iniciativa al agen- te urbanizador.}

El procedimiento de adjudicación de la iniciativa del agente urbanizador supone una mejora sustancial respecto a la regulación anterior, por dos aspectos esenciales. El primero es porque bastaba la mera iniciativa de la mayoría de los propietarios para paralizar la del agente urbanizador. El segundo porque para el supuesto de que sean los propietarios los adjudicatarios de la iniciativa, no se establecía como ahora el deber de reembolsar los gastos al agente urbanizador. La deficiente regulación es la que ha originado que en Andalucía muy pocas empresas hayan presentado iniciativas como agente urbanizador, salvando algunas excepciones como las de la empresa Urbasur SL.

El procedimiento de adjudicación se regula en el artículo 131 de la LOUA y comienza con la presentación en el Ayuntamiento de la documentación establecida en el artículo 130 y analizada en el epígrafe anterior 5.2.2. En el plazo de un mes y previos los informes técnicos precisos, el ayuntamiento desestimará la iniciativa o bien la aceptará, lo que supondrá someterla a un plazo de información pública por el plazo mínimo de un mes, con notificación a los propietarios afectados para presentación de alegaciones así como para en su caso presentar una iniciativa alternativa respaldada por los que representen más del $50 \%$ de suelo de la unidad de ejecución. 
A partir de este momento procedimiental se introducen las novedades, por cuanto no se adjudica como hasta entonces directamente a los propietarios, sino que éstos deberán presentar en el plazo de un mes desde la manifestación de su intención de presentar una alternativa la documentación correspondiente. Si se presentasen la documentación y se aprobase su iniciativa, deberán reembolsar los gastos del agente urbanizador.

Si los propietarios no anunciasen una alternativa o no presentasen la documentación correspondiente, continuará el procedimiento mediante la elaboración municipal de un pliego de condiciones para las bases para la adjudicación del concurso sobre unas bases orientativas de diseño urbano y unos criterios objetivos de adjudicación. Además se fijará un plazo no inferior a dos meses para el anuncio de alternativas a la presentada por el agente urbanizador, así como un plazo de un mes a partir de la finalización del anterior para su presentación.

Finalizado el segundo plazo se procederá en un plazo máximos de 10 días a la apertura de las plicas cerradas mediante un acto público y posteriormente en el plazo máximo de un mes a la adjudicación, sin que pueda quedarse desierta si sólo no se han presentado alternativas a la iniciativa inicialmente aceptada.

\section{El convenio del agente urbanizador y su actuación sin junta de compensación.}

La nueva regulación del agente urbanizador incluye uno de los elementos característicos en toda España de la regulación del agente urbanizador y es la figura del convenio urbanístico que suscribe con la administración. Es importante el convenio desde la perspectiva de que incluye los compromisos del agente urbanizador en relación a plazos, garantías o acuerdos con propietarios, así como también las posibles penalizaciones ante su incumplimiento.

En relación a la actuación del agente urbanizador una vez firmado el convenio con el Ayuntamiento, lo más importante a tener en cuenta es que no existe junta de compensación, siendo el agente urbanizador el responsable de la ejecución del planeamiento, es decir, el que en su caso redacta el planeamiento de desarrollo, tramita el proyecto de reparcelación y ejecuta o contrata las obras de urbanización.

$\mathrm{Al}$ no haber junta de compensación, en realidad el régimen jurídico entre los propietarios, el agente urbanizador y el Ayuntamiento es similar al del sis- 
tema de cooperación, de ahí que debería haber sido más razonable haber regulado este procedimiento en el marco del sistema de cooperación, cuyo régimen jurídico esta más regulado y es más conocido. La consecuencia de no incluirlo en el sistema de cooperación es que, por ejemplo, los propietarios no pueden constituir una asociación administrativa de colaboración, que en terminología de la legislación urbanística valenciana es la "agrupación de interés urbanístico".

La inclusión en el sistema de compensación sin la junta de compensación plantea innumerables dudas interpretativas, esencialmente respecto a la tramitación del proyecto de reparcelación y a la posibilidad de constituir una entidad urbanística colaboradora por los propietarios con fines de control y fiscalización. Respecto al proyecto de reparcelación, parece que será íntegramente tramitado por el Ayuntamiento aplicando de forma supletoria el Reglamento de Gestión Urbanística y respecto a la posibilidad de constituir una entidad urbanística colaboradora, parece que no es posible, sin perjuicio de constituir los propietarios una asociación de carácter privado.

Por este motivo, tanto las bases del concurso como el convenio urbanístico que suscriba el agente urbanizador con el Ayuntamiento deberá incluir un desarrollo normativo importante que sirva de base para resolver todas las dudas procedimentales de una regulación, que aunque muy positiva en líneas generales, podría haberse desarrollado algo más y quizá haber tenido una configuración distinta regulando el agente urbanizador como un nuevo sistema de actuación. 